\title{
Gender-Asymmetry in Dating Success of Korean Adoptees in the West ${ }^{*}$
}

\author{
Peter D. Dijkstra ${ }^{1,2}$, Daniel Schwekendiek ${ }^{3}$, Paul T. Y. Preenen ${ }^{4}$ \\ ${ }^{1}$ Behavioural Biology, Institute of Biology Leiden, Leiden University \\ ${ }^{2}$ Section of Integrative Biology, University of Texas, Austin, USA; \\ ${ }^{3}$ Center for Korean Studies, University of California, Berkeley, USA; \\ ${ }^{4}$ Group of Work and Organizational Psychology, University of Amsterdam, Amsterdam, The Netherlands. \\ Email: schwekendiek@berkeley.edu \\ Received March $3^{\text {rd }}, 2011$; revised April $6^{\text {th }}, 2011$; accepted May $7^{\text {th }}, 2011$.
}

\begin{abstract}
Overseas adoption from South Korea is a widespread phenomenon in the West. Adoption studies have focused on early development and post-adoption adjustment during childhood and socioeconomic success during adulthood. However, few studies deal with dating experiences and marital status of Korean adoptees, while these aspects are a key factor determining subjective well-being and sociocultural integration. Several studies and popular media highlight the status inferiority of Asian males compared to Asian females in the heterosexual Western courtship system. We therefore hypothesize that male Korean adoptees have more difficulties finding a partner than their female counterparts. Using a dataset stemming from a survey conducted among 290 adult adoptees living in the West, we indeed found that, after controlling for the effect of age and current income, males expressed more difficulty in finding a partner and were more likely to be single than their female peers in their adoptive Western country. This gender disparity may have implications for policy makers who are concerned with general well-being of transracial adoptees and Asian minorities in the West.
\end{abstract}

Keywords: Interracial Dating, Marriage, Adoption, Migration, Gender, Korea, Asia, USA, Europe

\section{Introduction}

Transracial adoption, that is, the adoption of children into families of a different race, is a widespread phenomenon in the West. For almost four decades of the last century, the greatest segment of international adoptees were from South Korea. Their popularity stemmed largely from the reliability and efficiency of the adoption practice resulting initially from the Korean war (1950-1953) that left many war orphans. Furthermore, push factors such as the economic and social burden of unwed mothers in Korean society, and pull factors such as the introduction of birth control devices and the female work participation in the West in combination with the commercialisation of adoptions drastically increased the number of babies sent from Korea to the West (Huebinette, 2006). Given the large number of (Korean) adoptees living in Western countries and the impact adoption can have on their lives, it is not surprising that a large body of literature investigates how well particular adoptee groups fare in their adoptive countries (Kim, 2010; Tuan \& Shiao, 2011).

These adoption studies, to date, have mainly focused on post-adoption adjustment and development during childhood and ethno-cultural identity formation during late adolescence and early adulthood (Basow, Lilley, Bookwala, \& McGillicuddy-DeLisi, 2008; Kim, 1995; Shiao \& Tuan, 2008). These studies revealed for example that Korean adoptees have done well in academic achievement and social adjustment compared to adoptees from other ethnic groups, in spite of different and

* Lin Huffman provided useful comments on earlier versions of the manuscript. The research was supported by a EU (International Outgoing Marie Curie fellowship) to P.D.D. The authors would also like to thank the anonymous referees for their comments that helped to improve this paper. serious adverse factors (Kim, 1995). Nonetheless, very few studies deal with dating and romantic opportunities of Korean adoptees, which is surprising since these aspects are widely viewed as key factors determining general well-being and social success. For instance, interracial marriages are often understood as an indicator of successful assimilation (Belot \& Fidrmuc, 2010). More importantly, being in a relationship has well-being enhancing effects since partners provide not only love, intimacy and sexual gratification (Diener \& Fujita, 1995) but also increased access to material and social resources (Soons \& Liefbroer, 2008; Wilson \& Oswald, 2005). An important question thus is how 'successful' Korean adoptees are in finding a partner in their adoptive Western countries.

Overall, transracial adoptees from Asia seem to be less often married than both the local population and white adoptees in the West (Rooth, 2002: p. 74). Moreover, several quantitative and qualitative studies observed that in the West, Asian males are less likely to be married to Whites than Asian females (Belot \& Fidrmuc, 2010; Jacobs \& Labov, 1995). This suggests that Asian males will face, among available heterosexual partners, a smaller pool of interested parties than Asian females. There are a number of explanations for this sex disparity, including lower socioeconomic status of Asian males compared to their White counterparts and gender-specific value of body height (Belot \& Fidrmuc, 2010; Chow, 2000). Perhaps more important than that, the media has an enormous bearing on how Asian men and women are perceived in the West. While Asian women are mostly hypersexualized in Hollywood and music videos, Asian men are portrayed as emasculated nerds, see Elaine H. Kim's documentary "Slaying the Dragon reloaded: Women in Hollywood and Beyond" (2010) or Charles Kuralt's 
documentary "Misunderstanding China" (1972). This is perhaps a remnant of the late $19^{\text {th }}$ century: when Asia began to economically rise and threaten Europe's hegemony in the world order, Europeans launched a 'yellow peril' campaign (Johnson $\&$ Poddar, 2005: p. 541). At the same time, the increasing number of Asian immigrants to the New World, and in particular to the United States, began to threaten white workers in the railroad and mining industry. This resulted in anti-Asian sentiments that were fuelled by Asian exclusionist groups (Takaki, 1998). Emerging prostitution among Asian immigrant women as well as a large number of Asian men becoming tailors, waiters, cooks, and most frequently laundrymen in the frontier town economy were exaggerated in white workers' propaganda to arouse anti-Asian sentiments (Eng, 2001: p. 92). This might have contributed to the historical stereotypization of Asian females as sexual objects and the emasculation of Asian men doing 'feminine' jobs. Another factor for the hypersexualization of Asian women is probably the emergence of U.S. military bases in the Pacific after World War II. This resulted in rampant bride trafficking and prostitution of poor Asian women around camptowns in Asia during the Cold War (Hoehn \& Moon, 2010).

We hypothesized that male Korean adoptees have more trouble finding a partner than female Korean adoptees. In a recent study, Shiao and Tuan (2008) found no gender effect on dating success or experience among Korean Adoptees in the USA, but this study was based on a specific, limited sample size of 58 individuals. Another problem of that study was that adopted parents were contacted by mail. However, previous research found that a considerable share of adopted parents oppose their Korean child's activities to go back to his or her roots (Jung et al. 2008), and that adult Korean adoptees in the United States often seem to move from rural to urban areas (in stark contrast to adult white adoptees) - perhaps as a result of maladjustment (Evan B. Donaldson Adoption Institute, 2009). In both cases, primarily 'well-adjusted' Korean adoptees are living with their adoptive parents or are still residing in their hometown - making it more likely that a large share of 'well-adjusted' respondents were apparently informed about the survey. A comprehensive study on gender and dating experience of Korean adoptees in the West is thus still lacking.

Using a dataset stemming from a survey conducted among 290 adult adoptees living in the USA, several Western European countries, and to a lesser extent in Australia (Jung, Gwon, \& Schwekendiek, 2008), we investigate whether Korean male and female adoptees experience different success rates in dating. Specifically, we hypothesize that first, male Korean adoptees report more difficulties finding a partner, and second, that male Korean adoptees are more likely to be single than their female counterparts.

\section{Methods}

\section{Sample and Procedure}

We used data of the Korean Ministry of Health, Welfare and Family Planning survey conducted among overseas adopted Koreans in 2008 (Jung et al., 2008). Portions of the survey data have been used in an earlier study (Schwekendiek, 2009). Through adoption associations and social media sites Korean adoptees from the United States, Europe and Australia were asked to fill out an online questionnaire which included among other variables, dating experience, marital status and demo- graphics. These associations were officially listed in the International Korean Adoptees Resource Book (Overseas Koreans Foundation, 2006), published by the Korean government in 2006 (and encouraged by the researchers to inform their members about the government survey in 2008). The survey collected data for 290 individuals. Individuals who answered 'other', 'don't know', or 'prefer not to say' to our questions regarding dating experience and marital status were excluded from the present analysis (dating experience: 26 cases; marital status: 3 cases).

In addition, we excluded 16 cases where the individuals reported to have either a homo- or bisexual orientation, or who did not report their sexual orientation (7 cases). Thus, this article exclusively attempts to investigate the gender-asymmetry in the Western dating market among Asian individuals with a heterosexual orientation. Worth noting, however, is that in the non-heterosexual Western world/sphere, Asian men and Asian women have somewhat different positions, where Asian men might even be privileged in the dating and mating markets compared to Asian heterosexual men, while the contrary might be true for their female counterparts. Considering the low number of non-heterosexual respondents in the survey, however, we cannot statistically test this hypothesis. In the survey, we find that an average of $3 \%$ reported to be homosexual with no noticeable differences between the USA (3\%) and Europe (3\%) (Jung et al., 2008: p. 68). Also, about $2 \%$ of the Korean adoptees self-reported to be gay and $3 \%$ to be lesbian. These rates are clearly within the average range among local populations in the West. For instance, previous research found that the prevalence of non-heterosexual couples ranges from $1 \%-9 \%$ for men and $1 \%$ $6 \%$ for women in metropolitan areas of the United States (Black, Gates, Sanders, \& Taylor, 2000: p. 148). Along similar lines, a previous study found that some $8 \%$ of men indicate to have non-heterosexual desires, while some $3 \%$ self-identify themselves as gay (Laumann, Gagnon, Michael, \& Michaels, 1994: 297). In this light, we can uphold that our heteronormative dating analysis does make perfect sense, as Korean adoptees do not seem to be disproportionably interested in same-gender partners.

Thus our final sample size consisted of a total of 241 heterosexual Korean adoptees (32.8\% male, $67.2 \%$ female). The mean age of the respondents was 30.1 years $(S D=7.00 ; S E=$ $0.45), 180$ of the respondents held a bachelor's or master's degree $(74.7 \%), 61$ respondents held a professional or no degree $(25.3 \%), 112$ participants lived in the US (46.5\%), 117 participants lived in Europe (46.5\%), and 11 respondents lived in Australia $(4.6 \%)$. Note that the sample size $(N=217)$ was lower in the analysis that included age and income since several respondents did not report these variables (age: 3 cases; income: 21 cases). The questionnaires were provided in English and French. As discussed elsewhere (Schwekendiek, 2009), these sample demographics are in line with the official demographics of the 170,000 overseas Korean adoptee population and earlier adoption studies, indicating that our sample is good enough to represent the overall adoptees' population from Korea.

It should also be noted that some associations, such as Global Overseas Adoptees' Link, an influential non-governmental organization run by Korean adoptees based in South Korea, claims that "upwards of 200,000 Korean children have been out of Korea for adoption" (see http://www.goal.or.kr/eng/? slms= info\&lsms $=1 \& s \mathrm{~s}=1 \& 1 \mathrm{~s}=1$ ). However, confirmation of these numbers are difficult in view of supporting statistical data provided by governments. 


\section{Measures}

\section{Dating Experience: Difficulty to Find a Partner}

In order to rate the degree of opportunities for romantic contact in the adoptive country, individuals were first asked the following: 'Did you have any serious problems finding a partner in your adoptive (Western) country? If so, how often?'. The four responses were $1=$ never, 2 = yes, once, 3 = yes, several times, $4=$ yes, often.

\section{Marital Status: The LikeLihood to be Single}

In order to determine the proportion of males and females that were currently in a romantic relationship, the individuals were asked: 'What is your marital status?'. The seven responses were: 1 = single, 2 = attached (boyfriend/girlfriend), $3=$ engaged, $4=$ married, $5=$ divorced, $6=$ widowed, $7=$ other . There was only one case reporting 'windowed', which was excluded from the analysis. We collapsed responses 1,5 and 6 into 'single', and 2, 3 and 4 into 'with partner', resulting in a dichotomous response variable.

\section{Covariates}

We controlled for age and current income level as measures that might plausibly covary with our response variables. To control for these factors individuals were asked: 'How would you describe your current income status?' The four responses were 1 = very high income, $2=$ high income, $3=$ middle income, $4=$ low income, 5 = very low income.

\section{Analysis}

We investigated differences between genders in the expressed level of difficulty of finding a partner using a Mann-Whitney $U$ test. To explore the effect of age and income on the gender difference, we used a Generalized Linear Model, treating the four possible responses as count data by employing a negative binomial link function. We used gender as the explanatory factor and age and current income as covariates. We compared the proportion of males and females that were currently in a romantic relationship using a chi-square test. We then explored the effect of age and income on the gender difference in a logistic regression, using the same explanatory variables as above. The Generalized Linear Model and logistic regression were run in a stepwise backward manner, sequentially removing the non-significant (interaction) effects using a threshold of $p=0.1$.

\section{Dating Experience}

As expected, males expressed more difficulty in finding a partner than females in their adoptive Western country (Mann-Whitney U test: $U=4317, p=.000002, N=241$ ). The sex disparity was retained when controlling for the effect of age and income (see Figure 1, gender: Wald $=14.74$, $\mathrm{df}=1, p$ $<.0001)$. Figure 1 suggests that the sex disparity tended to increase with age, mainly as a result of older males expressing more difficulty in finding a partner in contrast to the situation in females. However, this effect was not significant (gender $\mathrm{x}$ age Wald $=.597, \mathrm{df}=1, p=.44$ ). Current income was also retained in the model as a significant positive predictor (Wald $=5.347$, $\mathrm{df}=1, p=.021)$, see Table 2 .

\section{Dating Status}

Relatively more females $(65.2 \%)$ than males $(56.2 \%)$ were in current dating or marriage relationship (see Table 1). However, this difference was statistically insignificant (males: 39 single and 50 with partner; females: 62 single and 116 with partner, $\chi^{2}$ $=2.04$, $\mathrm{df}=1, p=.15$ ). A logistic regression (Figure 2 and Table 3) revealed, however, that the sex disparity in the likelihood to have a partner tended to increase with age (age $\mathrm{x}$ gender: Wald $=4.32, \mathrm{df}=1, p=.038)$, even when controlling for the positive effect of current income (Wald $=8.393, \mathrm{df}=1, p=$ 0.004). This means that older male Korean adoptees are more likely to be single than their female counterparts.

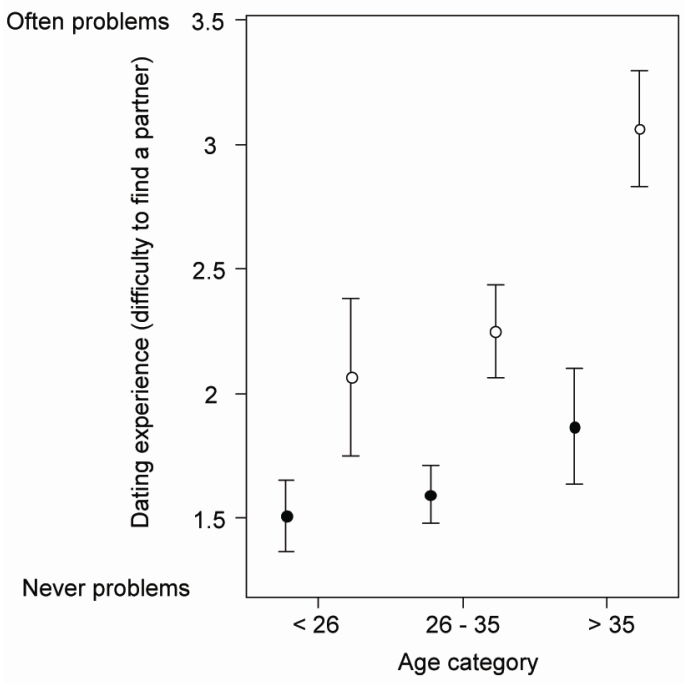

Figure 1.

Dating experience as a function of age; Notes: Dating experience (the difficulty to find a partner) for male (open, $N$ $=75$ ) and female Korean adoptees (closed, $N=143$ ) as a function of age. Shown are mean $\pm S E$.

Table 1.

Marital status by gender.

\begin{tabular}{ccc}
\hline Partnership status & Women & Men \\
\hline Single & $52(32.0 \%)$ & $32(40.5 \%)$ \\
Attached & $43(26.1 \%)$ & $23(29.1 \%)$ \\
Engaged & $5(3.0 \%)$ & $4(5.1 \%)$ \\
Married & $53(32.1 \%)$ & $15(19.0 \%)$ \\
Divorced & $8(4.8 \%)$ & $5(6.3 \%)$ \\
Widowed & $1(0.6 \%)$ & $0(0 \%)$ \\
No answer & $3(1.8 \%)$ & $0(0 \%)$ \\
\hline
\end{tabular}

Notes: number and percentage in each marital status group by sex (women, $N=$ 165 ; men, $N=79$ )

Table 2.

Regression on dating experience.

\begin{tabular}{ccc}
\hline Between subject effects & Wald & $p$ \\
\hline Gender & 14.74 & 0.000 \\
Age & 6.913 & 0.009 \\
Income & 5.347 & 0.021 \\
\hline
\end{tabular}

Notes: factors explaining variation in dating experience (the perceived difficulty to find a partner). Shown is the final model (Generalized Linear Model using the negative binomial link function). 
Table 3.

Regression on dating status.

\begin{tabular}{ccccc}
\hline Variable & $B$ & S.E. & Wald & $p$ \\
\hline Gender & 2.35 & 1.36 & 2.97 & 0.085 \\
Age & 0.06 & 0.03 & 3.82 & 0.051 \\
Income & -0.49 & 0.17 & 8.39 & 0.004 \\
Gender x age & -0.09 & 0.44 & 4.32 & 0.038 \\
Constant & -1.412 & 0.582 & 5.881 & 0.015 \\
\hline
\end{tabular}

Notes: factors explaining dating status (the likelihood to be single). Shown is the final logistic regression model.

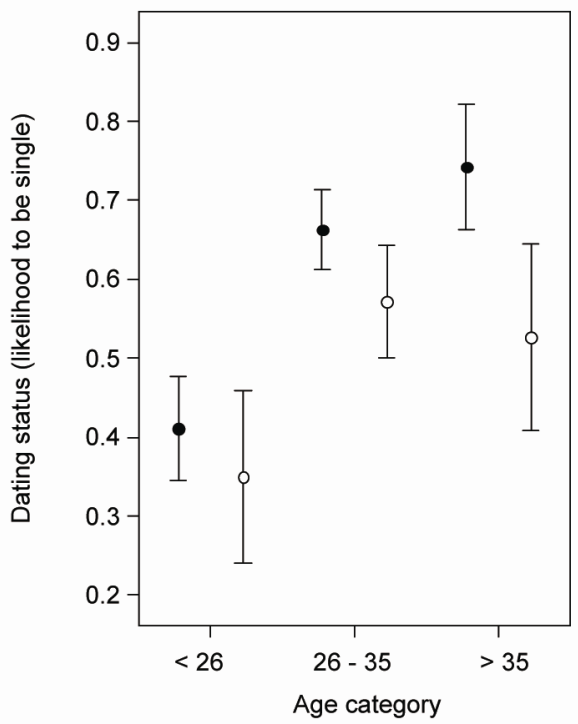

Figure 2.

Dating status as a function of age; Notes: Dating status for male (open, $N=82$ ) and female Korean adoptees (closed, $N=156$ ) as a function of age. Shown are mean $\pm S E$.

\section{Discussion}

The main purpose of this report was to compare the perceived degree of difficulty of finding a partner and the likelihood of being single in male and female overseas Korean adoptees. In accordance with our prediction, males expressed more difficulty in finding a partner than their female peers in their adoptive Western country. Moreover, more males than females were single, though this difference was not significant. More importantly, in the older age category males were more likely to be single than females.

To our knowledge, this study is the first to quantitatively present the gender asymmetry in dating success and marital status in Korean adoptees or any other transracial adoptees group. The gender differences in dating experience are consistent with previous studies of Asian American or Asian British intermarriage, reporting more Asian females than Asian males to be married to white spouses (Belot \& Fidrmuc, 2010; Chow, 2000; Jacobs \& Labov, 1995). Nonetheless, our findings contradict an earlier study that did not report gender differences among Korean adoptees (Shiao \& Tuan, 2008). The latter study may have failed to report gender differences, since its sample size was small and since probably more 'well-adjusted' individuals were informed by mail about the survey.
The sex disparity seems most likely the result of a Western mate preference defining Asian females, but not Asian males, as attractive. This preference asymmetry can be explained by several factors. First, the status inferiority of Asian males to White males in the Western courtship system might result from enhanced power and privilege accorded to Whites in largely Eurocentric societies, giving rise to higher racial status and attractiveness of White males (Chow, 2000). Secondly, mainstream stereotypes of Asian males and females may have shaped mate preferences in White people (Espiritu, 1997; Liang \& Ito, 1999). Moreover, Belot and Fidrmuc (2010) found that height distribution of white and Asian men, in conjunction with a simple preference for a taller husband, is sufficient to explain the observation that Chinese men are half less likely to be married to a white person than Chinese women in the UK and the USA.

Unexpectedly, we observed that the sex disparity in the likelihood to have a partner tended to increase with age. There are several mutually non-exclusive explanations for this and we can only speculate about how relevant they are here. A growing pan-Asian identity in the Western hemisphere may have improved the potential of Asian males in the Western courtship system (Chow, 2000). Other environmental or social factors that differ between the age cohorts may account for the observed gender and age interaction, although the underlying causal mechanisms are unclear. For example, in the USA a significant fraction of Korean adoptees spends early adulthood in college. The growing number of Asian college students in the last decades may have brought greater romantic opportunities for males from younger age cohorts (Shiao \& Tuan, 2008). More advanced statistical studies on this are needed to confirm this.

An important limitation of this study is that individuals were not selected randomly because no information of the adoptees was made available to the researchers by the adoption agencies or the government due to privacy protection issues of the adoptees and the Korean birth families. Instead, the survey was promoted through national and overseas adoptees' communities, which in turn were asked to contact their members to participate. Sampled adoptees initiating or staying in touch with overseas networks might have stronger interests (leading to a higher degree of self-selection) than the average adoptee; hence, possibly skewing some answers. However, when comparing answers of a control group in the survey that did not self-select themselves through such organizations but was informed about the survey by families and friends, no large distortions in the answers were found (Jung et al., 2008), suggesting that our data is good enough to broadly represent the Korean adoption population.

Another concern might be that we are overlooking the fact that Korean adoptees in the West can date both whites and other races, including their own Asian race. However, it seems that adopted Korean males are more often dating Asian partners than their female counterparts do (Jung et al., 2008: p. 69), which is perhaps exactly a result of local (white) partner constraints among Asian males (but not females). In this light, our analysis may even under-estimate the effects of dating problems among Asian men in the West.

Lastly, it is needless to say that many other unobserved factors affect the gender asymmetry in dating success among Korean adoptees. Worth noting is that the timing of the 'first contact' with other ethnic groups (Ellison \& Powers, 1994) seems to have a significant impact on choosing social networks in later life (including possibly partnerships). 
To end, our data show that Korean male adoptees face more difficulties finding a partner than their female counterparts. This may have implications for adoption policy makers who are concerned with the general well-being of adoptees. Overseas adoption from South Korea, and more recently China, is a widespread phenomenon in the West; debates about adoption policies and procedures, as well as how well adoptees fare in early life (Lien, Meyer, \& Winick, 1977; Teilmann, Pedersen, Skakkebæk, \& Jensen, 2006; Winick, Meyer, \& Harris, 1975) and adult life (Shiao \& Tuan, 2008), often attract a lot of attention. Some studies on Korean adoptees have revealed that they have done well in academic achievement and socioeconomic adjustment compared to other ethnic groups (Kim, 1995), but our study reveals that Korean male adoptees have considerably more troubles finding partners in their adoptive Western countries than their female counterparts. The ability to find a partner or spouse has a positive effect on a person's subjective well-being (Ribar, 2004; Soons \& Liefbroer, 2008). We therefore conclude that subjective well-being factors such as dating success and romantic opportunities should be seriously considered by policy makers in the discussion of general well-being of transracial adoptees and Asian minorities in the West.

\section{References}

Basow, S. A., Lilley, E., Bookwala, J. J., \& McGillicuddy-DeLisi, A. (2008). Identity development and psychological well-being in Korean-born adoptees in the U.S.. American Journal of Orthopsychiatry, 78, 473-480. doi: $10.1037 / \mathrm{a} 0014450$

Belot, M. V. K., \& Fidrmuc, J. (2010). Anthropometry of love: Height and gender asymmetries in interethnic marriages. Economics and Human Biology, 8, 361-372 doi:10.1016/j.ehb.2010.09.004.

Black, D., Gates, G., Sanders, S., \& Taylor, L. (2000). Demographics of the gay and lesbian population in the United States: Evidence from available systematic data sources. Demography, 37, 139-154. doi: $10.2307 / 2648117$

Chow, S. (2000). The significance of race in the private sphere: Asian Americans and spousal preferences. Sociological Inquiry, 70, 1-29. doi:10.1111/j.1475-682X.2000.tb00893.x

Diener, E., \& Fujita, F. (1995). Resources, personal strivings, and subjective wellbeing: A nomothetic and idiographic approach. Journal of Personality and Social Psychology, 68, 926-935. doi:10.1037/0022-3514.68.5.926

Ellison, C. G., \& Powers, D. A. (1994). The contact hypothesis and racial attitudes among Black Americans. Social Science Quarterly, 75, 385-400.

Eng, D. (2001). Racial castration: Managing masculinity in Asian America. Durham: Duke University Press.

Espiritu, Y. L. (1997). Asian American women and men: Labor, laws, and love. Thousand Oaks: Sage.

Hoehn, M., \& Moon, S. (2010). Over there: Living with the U.S. military empire from World War Two to the present. Durham and London: Duke University Press.

Huebinette, T. (2006). Comforting an orphaned nation: Representations of international adoption and adopted Koreans in Korean popular culture. Seoul: Jimoondang.

Jacobs, J. A., \& Labov, T. (1995). Sex Differences in intermarriage: Asian exceptionalism reconsidered. American Socio- logical Association Meeting, Washington.

Johnson, D., \& Poddar, P. (Eds.). (2005). A historical companion to postcolonial thought in English. New York: Columbia University Press.

Jung, A., Gwon, J., \& Schwekendiek, D. (2008). Survey on the status of overseas adopted Koreans and proposals for effective post-adoption services (in Korean). Seoul: Ministry of Health, Welfare and Family Planning.

Kim, E. J. (2010). Adopted territory: Transnational Korean adoptees and the politics of belonging. Durham: Duke University Press.

Kim, W. J. (1995). International adoption: A case review of Korean children. Child Psychiatry and Human Development, 25, 141-154. doi:10.1007/BF02251299

Laumann, E. O., Gagnon, J. H., Michael, R. T., \& Michaels, S. (1994). The social organization of sexuality. Sexual practices in the United States. Chicago: University of Chicago Press.

Liang, Z., \& Ito, N. (1999). Intermarriage of Asian Americans in the New York City region: Contemporary patterns and future prospects. International Migration Review, 33, 879-900. doi: $10.2307 / 2547356$

Lien, N., Meyer, K., \& Winick, M. (1977). Early malnutrition and "late" adoption: A study of their effects on the development of Korean orphans adopted into American families. American Journal of Clinical Nutrition, 30, 1734-1739.

Overseas Koreans Foundation. (2006). International Korean Adoptees Resource Book.

Ribar, D. C. (2004). What do social scientists know about the benefits of marriage? A review of quantitative methodologies. IZA Discussion Paper, No. 998.

Rooth, D.-O. (2002). Adopted children in the labour market-Discrimination or unobserved characteristics. International Migration, 40, 71-98. doi:10.1111/1468-2435.00186

Schwekendiek, D. (2009). Happy birthday? Official versus chronological age of Korean adoptees. Journal of Korean Adoption Studies, 1, 25-39.

Shiao, J. L., \& Tuan, M. H. (2008). Some Asian men are attractive to me, but for a husband...: Korean adoptees and the salience of race in romance. Du Bois Review, 5, 259-285. doi:10.1017/S1742058X08080132

Soons, J. P. M., \& Liefbroer, A. C. (2008). Together is better? Effects of relationship status and resources on young adults' well-being. Journal of Social and Personal Relationships, 25, 603-624. doi:10.1177/0265407508093789

Takaki, R. (1998). Strangers from a different shore: A history of Asian Americans. Boston: Little, Brown and Company. doi:10.1542/peds.2005-2939

Teilmann, G., Pedersen, C. B., Skakkebæk, N. E., \& Jensen, T. K. (2006). Increased risk of precocious puberty in internationally adopted children in Denmark. Pediatrics, 118, e391-e399.

Tuan, M. H., \& Shiao, J. L. (2011). Choosing ethnicity, negotiating race: Korean adoptees in America. New York: Russel Sage Foundation.

Wilson, C. M., \& Oswald, A. J. (2005). How does marriage affect physical and psychological health? A survey of the longitudinal evidence. IZA Discussion Paper, No. 1619.

Winick, M., Meyer, K., \& Harris, R. (1975). Malnutrition and environmental enrichment by early adoption. Science, 190, 1173-1175. doi:10.1126/science. 1198103 